\title{
A CONEXÃO DO SISTEMA DE GESTÃO DA QUALIDADE TOTAL (SGQ) COM A GESTÃO DA INOVAÇÃO (GI)
}

Claudia Maria Camilher Jamal claudia.jamal@int.gov.br Instituto Nacional de Tecnologia INT, Rio de Janeiro, RJ, Brasil.

\section{Marcus Vinícius Albrecht} Anversa

marcus.anversa@int.gov.br Instituto Nacional de Tecnologia INT, Rio de Janeiro, RJ, Brasil.

\section{Paulo Antônio de Souza}

\section{Chacon}

pchacon555@gmail.com Instituto Nacional de Tecnologia INT, Rio de Janeiro, RJ, Brasil.

\section{RESUMO}

A produtividade da indústria brasileira auferiu novo fôlego com o movimento da qualidade e com as empresas que investiram em seus SGQs e ganharam em competitividade. Após isso, outro movimento se iniciou, abraçando governo, empresas e ICTs: o movimento pela inovação. A proposta do presente artigo é apresentar a importância do Sistema de Gestão da Qualidade (SGQ), considerando a pauta pró-inovação que é emblemática da agenda industrial brasileira. Identificar, dentre os atributos de um SGQ, quais, efetivamente, remetem à inovação. A metodologia conta com análise crítica das concepções da Qualidade para a Inovação. Os autores pontuam que ter um SGQ estruturado é característica comum a empresas inovadoras, admitindo-se daí que a Organização usufrua de dividendos associados à criatividade. Por fim, os fatos resumidos neste artigo ampliam a percepção de que existe um interessante e auspicioso grau de alinhamento entre qualidade e inovação. A primeira é um input à segunda, comprovando a conjunção Biunívoca.

Palavras-chave: Sistema de Gestão da Qualidade; Inovação; Conjugação Biunívoca 


\section{INTRODUÇÃO}

Muito embora a literatura seja escassa e um tanto controversa quando aborda conexão entre gestão pela qualidade e inovação, alguns estudiosos destes institutos, acompanhando o pensamento de James Westphal et. al. (1997), como Shahid Yamin et. al. (1997) e Juett Cooper (1998), consideram a Qualidade Total uma forma de inovação. Na verdade, pode-se relatar a existência de uma perfeita relação entre Qualidade e Inovação, constituindo um componente fundamental para o sucesso das organizações. A Qualidade estimula e fornece ferramentas adequadas à inovação enquanto mira na maior eficácia e capacidade de atender a expectativa, bem como a cativar os clientes. Por sua vez, a Inovação propriamente dita se assume como um sistema vital para o sucesso e sustentabilidade das empresas (Saraiva e D’Orey, 1999). Acompanhando a análise de Bruce Han et. al. (2007), as empresas têm adotado práticas de Sistema de Gestão da Qualidade Total (SGQ) como estratégia de resposta aos requisitos dos clientes. É uma abordagem de gestão na qual a principal preocupação é ir ao encontro das necessidades e expectativas dos clientes através da integração de todas as funções e processos da organização, visando alcançar uma melhoria contínua da qualidade dos bens e serviços.

A missão primordial das empresas é a criação de valor, sendo essencial desenvolver a sua atividade de forma eficiente, conjugando adequadamente os recursos disponíveis. É desta forma que a empresa atuante no mercado consegue sobreviver e continuar a operar, mantendo os custos sob controle e majorando receitas. Tem-se, assim, a Qualidade e a Inovação emergindo como conceitos vitais para a sobrevivência das empresas em face de um ambiente generalizado de grande competitividade, de elevada mudança e de enorme velocidade, no qual só os mais ágeis e criativos serão capazes de subsistir (Saraiva e D’Orey, 1999).

É nesse contexto que as Instituições Científicas e Tecnológicas (ICTs) apresentam-se como entes de cooperação. Conectando-se ao sistema produtivo como fornecedoras de novos produtos e processos por elas prospectados e desenvolvidos, derramam conhecimento e sugerem inovações que passam a proporcionar o sucesso e sobrevivência da empresa. Um primeiro indicativo desta interação Qualidade e Inovação talvez possa ser buscado num dos "mantras" da Qualidade que é "fazer certo a coisa". Ainda que se busque apenas fazer "certo a coisa" (processo), eventualmente, há o seu intrínseco poder de iluminar aspectos inusitados que levem também a novos produtos.

\section{O Sistema de Gestão da Qualidade (SGQ), histórico e contextualização}

Durante a II Guerra Mundial, as empresas e organizações japonesas, berço dos atuais métodos de Gestão da Qualida- de (SGQ) em uso, baseavam o seu controle de qualidade nos Padrões Normativos Britânicos. Esse padrão britânico, também adotado pelos estadunidenses, é reconhecido como berço da Estatística Moderna. Entretanto, por influência do método administrativo criado por Frederick Taylor (18561915), considerado o mais moderno na época, no qual os trabalhadores deveriam orientar-se pelas especificações determinadas por especialistas, o Japão competia em custo e preço, mas não em qualidade. Os produtos eram baratos e ruins (ISHIKAWA, 1993). Esse problema trouxe grande preocupação às forças de ocupação americana no Japão (19451952).

Através dos cursos e treinamentos de Controle da Qualidade, constituídos pelo Grupo de Pesquisa em Controle de Qualidade (GPCQ), ministrados por especialistas estadunidenses, entre eles o Dr. Edward Deming (1900-1993), abordava-se o sistema focando principalmente na melhoria do gerenciamento da qualidade. Chegava-se a afirmar que em torno de $85 \%$ dos problemas advinham da responsabilidade gerencial. Além disso, suas propostas revelariam um conteúdo humanístico quanto à valorização dos empregados de "chão de fábrica" e quanto à procura do comprometimento e conscientização por parte desses. Logo após essa criação, os membros do GPCQ passaram a escrever seus próprios textos e a evitar o uso de obras traduzidas.

Na década de 1950, foi criado o Círculo de Controle de Qualidade (CQC) cujo objetivo era a melhoria da qualidade através da automotivação assim obtendo a contribuição espontânea dos operários. O CCQ foi logo aceito na Coreia do Sul e em Taiwan, chegando ao Brasil em 1971 e aos Estados Unidos em 1976 (Chiavenato, 2002). Enquanto no Japão, desde o fim da II Grande Guerra, o controle de qualidade estava em evolução, simultaneamente nos Estados Unidos iniciou-se uma época de grande abundância e prosperidade. Carmen Fonseca (2004) visualiza nessa fase pós-guerra a ocorrência da grande demanda por produtos estadunidenses e a consequente produção elevada, mas também trazendo a consequente contrapartida da seletividade minorada e, obviamente, algum prejuízo notado na qualidade de seus produtos e processos. A falta de um foco mais consistente aos aspectos da qualidade foi cobrada na competitividade da economia dos Estados Unidos a partir do final dos anos 1970 frente às nações de economia em plena ascensão, em especial, o Japão. Um dos efeitos notados foi a ocorrência da primeira grande greve no centro de sua indústria automobilística, Detroit, resultante da perda da competitividade e, consequentemente, de mercado aos similares japoneses. Nas décadas seguintes, acirra-se a concorrência com a emergente China, Coreia do Sul, Taiwan, etc., que seguiram a receita japonesa, isto é, o foco na gestão da qualidade, seguido na busca da inovação. Dentro da receita, ressaltam-se as ações para elevar o grau de escolarização de suas populações, a busca do contínuo desenvolvimento tecnológico e 
das citadas inovação e gestão da qualidade, tudo visando melhorar a competitividade de seus produtos, processos e serviços com a consequente abertura de novos mercados.

Como observado, os gestores japoneses desde o pós-guerra passaram a seguir um modelo próprio que pode ser resumido em educação em controle de qualidade para todos os níveis da empresa e educação em longo prazo. 0 primeiro passo no controle de qualidade é conhecer a demanda do cliente. Quando não adequadamente atendida, há de se buscar a causa, inserindo aqui lugar para algumas ferramentas. Dessas, importante é a utilização do Diagrama de Causa e Efeito (chamado também de Diagrama Ishikawa ou Diagrama Espinha de Peixe). Essa ferramenta de Controle da Qualidade (CQ) é de grande importância. Num primeiro momento, a ferramenta presta-se a identificar as causas do efeito inesperado. Entretanto, é quase regra que, nesse processo da investigação, ações de melhoria associadas a novos processos e produtos venham a ocorrer. E, é claro, referindo-se às atitudes pré-inovação. Nesse mesmo diapasão, outras ferramentas, a exemplo do QFD (Quality Function Deployment / Desdobramento de Função Qualidade) acabam, no curso e ao cabo, ensejando melhorias e/ou ideias para inovação.

No Brasil, as primeiras experiências com os círculos de controle de qualidade começaram no final dos anos 1970, praticadas na Walita e na Volkswagen, de modo que, nos anos seguintes, várias empresas passaram a seguir o sistema. Nos anos 1990, o modelo japonês já havia deixado de ser exclusivo desse país, tornando-se o padrão universal das empresas que pretendiam alcançar e manter a capacidade de competir em escala global (Maximiano, 2000). Várias das ferramentas e métodos de trabalho que foram criados e aperfeiçoados através dos anos são provenientes do sistema japonês, que é diferenciado pela simplicidade de seus componentes: eficiência, qualidade e participação dos funcionários nas decisões. Algumas são bastante aplicadas, tais como: Kanban, Kaizen, Just-in-time, 5S, Círculos de Controle de Qualidade (CCQ), Diagrama de ISHIKAWA (Causa e Efeito ou Espinha de Peixe), Método de Análise e Solução de Problemas (MASP), Gerenciamento pelas Diretrizes (GDP), Kaizen, e outros.

\section{A qualidade no Brasil e seu impacto}

As questões relativas à especificação da normalização e de critérios de qualidade a serem cumpridos pelas empresas existiam desde 1947, com a criação da Internacional Organization for Standartization (ISO), sediada em Genebra, na Suíça, que congrega organismos de normalização nacionais. A sigla ISO é uma referência à palavra grega ISO, que significa igualdade. A atividade principal da organização é elaborar padrões para especificações e métodos do trabalho nas mais diversas áreas da sociedade. Nestes tempos de alta competitividade e de exigência dos clientes, o mercado requer das empresas desempenhos cada vez maiores, requerendo sistemas produtivos e de gerenciamento mais eficazes e eficientes.

Com o Governo de Fernando Collor de Mello, iniciado em 15 de março de 1990, as empresas brasileiras tiveram maior exposição devido à abertura da economia do país ao mercado internacional. Essa mudança de diretriz econômica provocou nas indústrias locais a luta pela própria sobrevivência, considerando a concorrência que se configurou. Consequentemente, passou a ser vital a busca do aumento da qualidade e da competitividade. Em linha, procurou-se modernizar e aperfeiçoar a gestão patrimonial (ativos operacionais) e empresarial. As palavras "pesquisa", "desenvolvimento" e "inovação" começam a frequentar, embora de forma tímida, a pauta de conversas dos empresários e empreendedores. Parecia estar delineado, então, o momento propício para consolidar o sistema de gestão pela qualidade total, e com anseios mais amplos.

Esse novo método de gestão passou a ser o foco dos vários setores da economia, sendo o começo de uma nova era na gestão e reforçada com a criação do Movimento Brasileiro pela Qualidade, do Prêmio Nacional da Qualidade (PNQ) e do Programa Brasileiro de Qualidade e Produtividade (PBQP). Com isso, os resultados começaram a aparecer, assim como o emprego da Qualidade, combinado com outros fatores, como o modo de ação do Estado em sua intervenção e controle da economia, da exigência do empresário me maior qualificação, do começo em várias empresas na implantação de seus departamentos de Pesquisa \& Desenvolvimento, visando a criação de novos produtos, processos ou serviços e assim fazendo frente aos desafios de uma economia em fase de globalização. Segundo Organização para a Cooperação e o Desenvolvimento Econômico (OCDE), a taxa média anual da Produtividade Industrial Brasileira, que foi de -0,5\% no período 1985-1990, passou para + 8,3\% de 1990 a 1995 (sendo -2,2\% em 1990). Segundo Carmen Fonseca (2004, p. 43), os setores produtivos e de serviços já mostravam grandíssimos ganhos na primeira metade da década de 1990; o tempo de montagem de um veículo foi alterado de $48 \mathrm{~h}$ para $28 \mathrm{~h}$, bem como de televisores, de 100 para $25 \mathrm{~min}$. Já a produção de veículos por empregado aumentou de 9 para 20. Outro indicador que demonstra os efeitos do emprego do método da qualidade foi o rápido crescimento do número de certificados pelas Normas da Série ISO 9000 (35 até 1991; 948 até 1995 e 5.285 até 1999).

Talvez, o grande legado desse movimento - e aqui já se reforça hipótese proposta do artigo - seja o fato de que muitas empresas que efetivamente adotaram o Sistema de Gerenciamento pela Qualidade Total, algumas concorrendo e ganhando prêmios concernentes às suas práticas, figuram 
também como empresas mais inovadoras do Brasil, como a Vale, WEG Motores, Votorantim e a EMBRACO. Os fundamentos que pavimentaram suas trajetórias bem ascendidas, considerando a gestão da inovação, serão retratados nas seções seguintes.

\section{A inovação no Brasil}

Talvez, de uma forma mais organizada e sistemática, a gestão baseada na inovação no Brasil tenha se iniciado na virada no limiar do século XX/XXI. Com efeito, é desse período a LPI - Lei da Propriedade Industrial ${ }^{1}$, que vai regular os direitos e deveres àquele cidadão, residente ou não, que apresentasse produto ou processo novo e dotado de atividade inventiva.

É dos idos de 2002-2003 a discussão com a sociedade e comunidade acadêmica sobre o texto que seria a Lei da Inovação ${ }^{2}$. A sua redação é de fins de 2004 e o decreto que o regulamentou é de início de 2005. Por oportuno, cabe citar outro marco importante desse período, a Lei $13243^{3}$, considerada o Marco legal da Ciência, Tecnologia e Inovação. Em 2018, saiu o decreto no 9.283, que a regulamenta.

Segundo José Cassiolato e Helena Lastres (2003, p. 24), o Sistema de Inovação

"pode ser definido como um conjunto de instituições distintas que contribuem para o desenvolvimento da capacidade de inovação e aprendizado de um país, região ou localidade.

1 Lei no 9.279, de 14 de maio de 1996 - Regula os direitos e obrigações relativos à propriedade industrial. Propriedade industrial é o conjunto de direitos que compreende as patentes de invenção, os modelos de utilidade, o desenho ou modelo industrial, as marcas de fábrica ou de comércio, as marcas de serviço, o nome comercial, ajudando na repressão da concorrência desleal e das falsas indicações geográficas. A propriedade industrial constitui-se através de um registro prévio no INPI.

2 Lei no 10.973, de 02 de dezembro de 2004 - Estabelece medidas de incentivos à inovação e à pesquisa científica e tecnológica no ambiente produtivo e tem como objetivo criar um ambiente propício para aumentar o envolvimento das empresas no desenvolvimento de projetos inovadores que levem a gerar novos produtos e processos. Busca-se, com ela, uma elevação do nível de parcerias entre empresas, universidades e institutos científicos e tecnológicos para que ganhem força e estimulem o processo de inovação.

3 Lei no 13.243, de 11 de janeiro de 2016 - dispõe sobre estímulos ao desenvolvimento científico, à pesquisa, à capacitação científica e tecnológica e à inovação. As suas novas regras criam mecanismos para integrar instituições científicas e tecnológicas e incentiva investimentos em pesquisa.
Constitui-se de elementos e relações que interagem na produção, difusão e uso do conhecimento. A ideia básica do conceito de sistemas de inovação é que o desempenho inovativo de uma economia como um todo depende não apenas do desempenho de organizações específicas, como empresas e organizações de pesquisa, mas também de como elas interagem entre si e com o setor governamental, na produção, distribuição e uso de conhecimentos, em prol da competitividade, crescimento econômico e bem-estar social". (Cassiolato e Helena Lastre, 2003, p. 24).

Efetivamente, podem-se observar as inter-relações e componentes do Sistema Nacional de Inovação (SNI) do Brasil na Figura 1.

Estudos relacionados à teoria e Gestão de Inovação distinguem o conhecimento como sendo o maior de seus combustíveis. Ao mesmo tempo encontram-se associadas diversas dimensões de learnings, como postulados por Arrow, Materba, entre outros. Dessas dimensões, chamamos a atenção para o learning by Using e o learning by Doing. Esses já estavam presentes em práticas de empresas japonesas, pouco antes do século XX, e prenunciaram, portanto, as conexões que a hipótese deste artigo sugere.

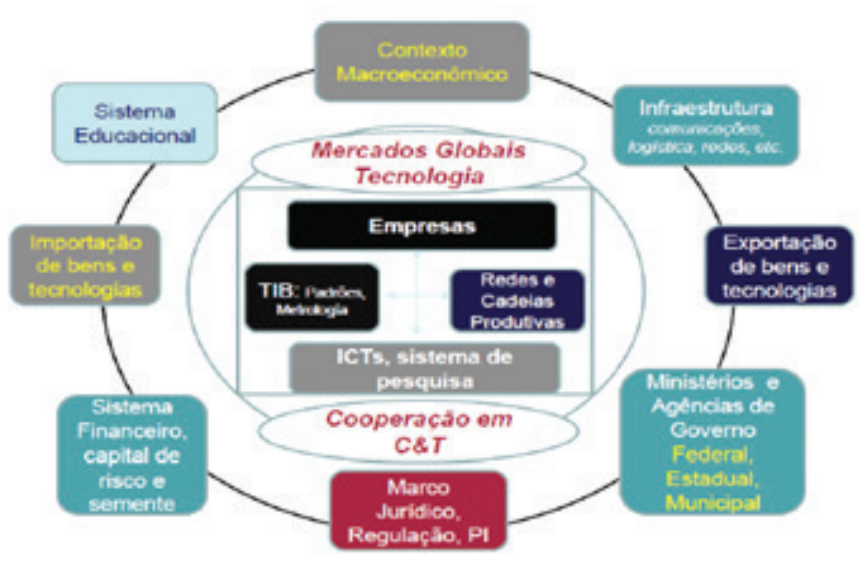

Figura 1. Sistema Nacional de Inovação. Fonte: Alvaro Diaz apud Salerno, 2012.

Com o advento das novas teorias de crescimento (endógeno) que privilegiam o conhecimento, o investimento no capital humano e o contexto histórico-geográfico, novas dimensões colocam-se como o learning by Learning e o learning by Interacting, além do learning by Searching. Esses são referenciais, alguns inspirados pela década de 1990, que reforçam e aproximam os dois modelos. Enquanto a dimensão do "using" aproxima a empresa do cliente (e de suas necessidades; "isso é qualidade"), as dimensões do searching e do 
interacting "podem estar indo" ao encontro de surpreendê-lo, com a geração do inusitado ("a inovação").

\section{METODOLOGIA}

A proposta do presente artigo é trazer uma discussão a respeito da inter-relação, muitas vezes não plenamente decodificada, existente entre a Gestão da Qualidade e a Gestão da Inovação. Há aspectos da primeira que podem impactar positivamente na segunda? Quais são eles? De que forma? Com o fito de responder a essas inquietações, segue a dissertação dos argumentos.

$\mathrm{O}$ artigo faz uso de metodologia que recorre à pesquisa exploratória em bases de dados científicas no horizonte temporal recente. Nele, temos as seguintes seções que abordam o histórico e a contextualização do SGQ, seu impacto, a Inovação no Brasil, a conjugação Biunívoca da Qualidade e Inovação e os resultados que foram obtidos.

\section{Qualidade e inovação, uma conjugação biunívoca}

Segundo Oliveira (2015), a ISO 90012015 trouxe em seu requisito de Melhoria, pela primeira vez desde que a norma foi criada em 1987, a palavra "Inovação". Está lá de forma tímida em uma nota no requisito 10.1, como um exemplo de melhoria. Não é um requisito, mas, um reconhecimento da ISO e de que ela é uma das formas possíveis de melhoria. Se a mesma ocorrer na empresa, ela deverá ser "captada" pelo Sistema de Gestão da Qualidade e tratada como outros tipos de melhorias.

Juntamente com a análise de riscos, a investigação da causa, dentre outras, a busca por inovação pode ser uma importante estratégia para reconfigurar um negócio. Termo indissociável de inovação, o risco (sua análise) dá "liga" aos dois sistemas em foco. Inovar presume assumir certos riscos, os quais se não bem analisados, podem resultar em efeitos indesejados, e isto é falta de qualidade.

Não obstante, estudos mostram que as empresas que se destacam por possuir Programa de Gestão da Qualidade (PGQ) robusto também são vistas como empresas inovadoras. Elas têm em suas estratégias a inovação como um forte vetor. Mais que isso, além de desenvolver esta competência, a transformaram em função vital. Assim, tais empresas possuem comitês ou mesmo departamentos responsáveis por fazer com que a inovação ocorra. Tal como as áreas de gestão da qualidade (que não são responsáveis pela obtenção da qualidade, mas estabelecem as condições para que a operação produza a qualidade), estas áreas de inovação não são diretamente responsáveis por inovar, mas sim por proporcionar um ambiente propício à concepção e curso da inovação. A área corporativa que cuida da inovação, tal qual a da qualidade, funciona como apoio a esse fim. A inovação propriamente dita é efeito do conhecimento, quer seja acumulado ou interativo.

Tais áreas dentre outras atribuições podem ser responsáveis pela gestão do conhecimento, pela busca de cooperação externa, por criar uma rede em que o conhecimento seja compartilhado, por avaliar e, junto aos responsáveis das demais áreas, assumir riscos, que são requisitos da norma ISO 90012015.

Para ter uma ideia do nível de conexão que associa a busca da qualidade e a inovação, é interessante assinalar um registro repetidamente observado na PINTEC. Praticamente em todas as edições da pesquisa, quando perguntados sobre evidências da inovação na empresa, os empresários identificam as melhorias na qualidade. Aperfeiçoando seu $S G Q$, as empresas têm a percepção de que acabam inovando. $E$, de fato, inovam.

Como afirmado anteriormente, a implantação de princípios do SGQ cria uma cultura organizacional favorável ao desenvolvimento de atividades de inovação, como também deduz Mohamed Zairi (1994). Segundo Daniel Prajogo e Amtik Sohal (2004a, 2004b), os princípios da Gestão da Qualidade são semelhantes aos princípios da inovação. Portanto, a Gestão da Qualidade pode impulsionar e tornar a organização mais empenhada na criação de um clima sustentável à inovação (Zairi, 1994). Complementando a visão positiva entre o SGQ e a inovação, a melhoria contínua, a participação no processo de decisão, o apoio da gestão de topo, o trabalho em equipe e a cultura "aberta" da organização, são elementos-chave comuns ao SGQ e à inovação, sendo o desenvolvimento de práticas de SGQ traduzido na incorporação de ingredientes fundamentais ao estabelecimento e desenvolvimento de inovação (Prajogo e Sohal, 2003, 2004).

Existem várias empresas que ilustram a aplicação do SGQ, entre elas a LatAço, uma das líderes brasileiras no mercado de embalagens metálicas (latas), eles utilizam-se de um programa de "geração de ideias", que se trata de uma atividade impulsionadora da criatividade e inovação da empresa. É um mecanismo de gerar ideias obtidas pela equipe de $P \& D$ da empresa, mas também envolvendo os demais funcionários, visando uma conexão aos efeitos de ordem paradigmática que iluminam o caminho para inovação de dado produto, processo ou serviço. Trabalhar com a geração de ideias é um grande desafio para as empresas. No processo de inovação, é preciso que haja um esforço constante em gerar um grande fluxo de ideias, visto que essa é a primeira etapa desse processo. Para isso, são estruturadas técnicas de apoio à geração de ideias como: Método dos Seis Chapéus, Brainwriting - Método 6-3-5 e Modelo $5 \mathrm{~W}+1 \mathrm{H}^{4}$.

4 Estes métodos não foram aqui detalhados por conta do escopo e limitação do artigo. Entretanto, é possível obter maiores infor- 
A empresa LatAço, estudada por Wander de Lima (2011), prioriza um mecanismo de geração de ideias vindas dos funcionários. Essa atividade de criação de ideias é considerada o carro-chefe do sistema de inovação da empresa, consistindo em um programa de estímulo aos funcionários de todas as áreas e funções. Estímulo a darem constantes sugestões, críticas e ideias sobre produtos, ambiente de trabalho, práticas administrativas, processos de fabricação, o dia-dia operacional e formas de gestão da empresa. Wander de Lima (2011) apreende uma frase obtida de um dos seus entrevistados na empresa que define bem o impacto da atividade de geração de ideias na inovação: "as ideias criativas influenciam o aumento da produtividade e estimulam o ambiente inovador interno". Esta atividade nasceu como um programa de ideias sobre melhorias em processos, mas com o passar do tempo tornou-se o principal canal de diálogo entre a alta administração e o pessoal operacional, e uma fonte importante de novas ideias e inovação para produtos.

Como observado, a busca do efeito paradigmático, isto é, a quebra de paradigmas, obteve-se com o SGQ. Na busca da inovação, houve a necessidade de mudança, rompimento de modelos burocráticos e centralizadores que eram os paradigmas a serem vencidos, além da ocorrência de constante renovação que trouxe vários benefícios para a gestão, como: a descentralização, a valorização do capital intelectual, a valorização do impacto do elemento humano.

Por que podemos afirmar que a relação entre "Qualidade" e "Inovação" é biunívoca? Quando concebemos uma inovação, algo novo - ainda que o seja - a ausência da qualidade vai tornar a incerteza mais crítica. A insuficiência ou ausência de qualidade traduziria ao cliente em algo "sem valor", o que denotaria não ser de fato uma inovação. $O$ fator positivo de utilizar as metodologias da qualidade é o de permitir que o conhecimento gerado no processo de inovação seja potencializado. Além disso, também permitir criar um ciclo virtuoso PDCA (Plan - Do - Check - Act ou Adjust), para além da sua captação em normas, ou outros referenciais, que permitem o seu uso generalizado e o seu sucesso no mercado.

A relação biunívoca Inovação e Qualidade, portanto, conjuga esforços para o aumento da produtividade e da competitividade. De fato, Inovação e Qualidade partilham das metodologias e conceitos que devem ser encarados numa perspectiva global, assentados nas mesmas bases: os processos, as pessoas e as organizações (Santos, 2013).

Inovar pressupõe transformar conhecimento em valor. Ter boas ideias e base de conhecimento. Entretanto, não

mações de suas metodologias e aplicações através da seguinte página da internet mantida pela AEVO, https://blog.aevo.com. $\mathrm{br} /$ metodos-geracao-de-ideias-6-chapeus-brainwriting-5w1h/. Acesso em: 30 mai. 2019. ter a capacidade de gerir de modo planejado e sistemático pode resultar em desestímulo ou fracasso. Com efeito, para que estes fiquem retidos na organização, além da falta dos recursos para sua conversão em valor, a conjugação negativa desses fatores propiciará a não criação de interesse prático e de riqueza das tidas boas ideias.

\section{RESULTADO E DISCUSSÃO}

O anuário "Valor Inovação Brasil 2018", publicado pelo Valor Econômico, apresentou o ranking das 150 empresas mais inovadoras do país. Também editou matérias sobre iniciativas, investimentos e exemplos práticos da atuação das 10 empresas mais inovadoras e das líderes em cada um dos 21 setores analisados. A Figura 2 abaixo revela parte do ranking, considerando as dez empresas mais inovadoras.

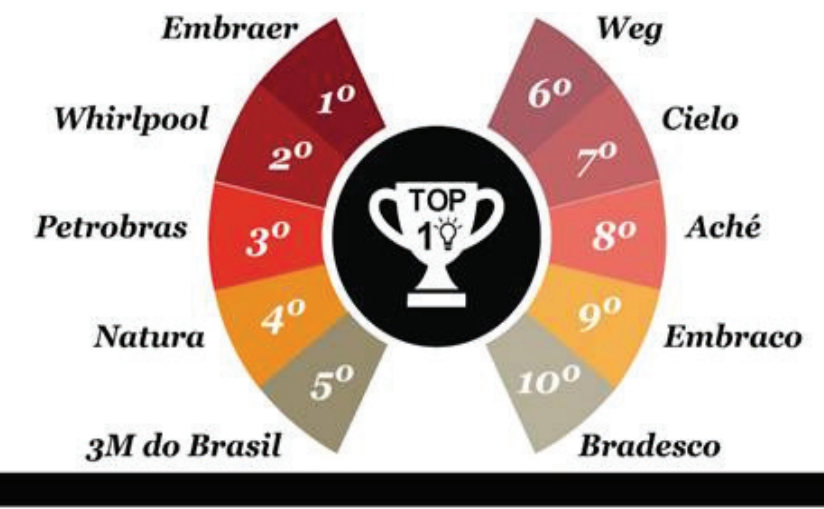

Figura 2. Ranking das 10 empresas mais inovadoras. Fonte: Valor Inovação Brasil, 2018.

Analisando as 10 primeiras empresas neste ranking, todas têm a certificação ISO 9001. A implementação de processos de qualidade nestas empresas e no mercado em geral, muitas vezes, vem do próprio mercado em que estão inseridas. A Embraer, considerada a empresa mais inovadora brasileira, para poder fornecer seus produtos para o mercado americano, foi obrigada pelo mesmo a seguir essas normas e já nos anos 1980 criou seu SGQ com base no sistema MIL-Q-9858.

A segunda colocada neste ranking, Whrilpool, maior fabricante de eletrodomésticos e presente no país com as marcas Brastemp, Consul e KitchenAid é certificada pelo Sistema de Gestão Integrada (SGI) que a credencia com as normas ISO 9001 (Qualidade), ISO 14001 (Meio Ambiente) e OHSAS 18001 (Saúde e Segurança Ocupacional). A Petrobras, 3a empresa neste ranking, além de ser certificada, exige de seus fornecedores as mesmas certificações. Já a 4a empresa, Natura, é líder no mercado brasileiro de cosméticos e certificada desde 2004. Recentemente, adquiriu a Avon e tornou-se globalmente a 4a empresa de seu setor. 
Todas essas empresas têm em comum um forte investimento na qualidade de seus processos e produtos. Em parte, parece estar sugerido que parte de suas inovações vieram na tentativa de resolver problemas inerentes à qualidade para garantir a satisfação de seus clientes. Analisando esses dois conjuntos, o do SGQ e da Inovação, percebe-se que eles são biunívocos, onde a qualidade impacta na gestão da inovação.

Sistemas de gestão da qualidade criam ações padronizadas, gerando um sistema de melhoria contínua focado em inovação. Ao se planejar e desenvolver soluções que atendam as solicitações dos clientes, cria-se ambiente auspicioso às inovações, de várias formas, e um melhoramento contínuo e sustentável de seus processos e métodos de controle.

\section{CONCLUSÃO}

O presente trabalho focou no estudo envolvendo as gestões da qualidade e inovação. Nele foi procurado identificar os aspectos inerentes ao do impacto da qualidade sob a inovação. Através do seu resgate histórico e de sua contextualização no Brasil, foi possível de forma enfática, posicioná-los através da cronologia, os efeitos sobre as causas.

Foram reunidas evidências objetivas da importância de algumas ferramentas da qualidade, enquanto impulsionadoras de ideias, ou mesmo o papel de estimular criações inovadoras. Nessa linha, o diagrama e causa-efeito, o QFD, o círculo de controle de qualidade e a geração de ideias funcionam no SGQ como verdadeiros inputs inovadores.

Em outro ângulo, observamos a interação com clientes e fornecedores, elementos esses fortemente presentes nos sistemas de Gestão da Qualidade. Eles são prestativos ao inserirem-se como agentes que proporcionam a gênese de efeitos desejados, de uma sequência de aprendizados que demandam mais aprendizado, fundamentando-se na interação e na pesquisa, aspectos que, não são apenas conjecturais, mas pragmaticamente concorrem à inovação.

É emblemática a análise das empresas ditas mais inovadoras no ranking do Valor Econômico, observa-se que o contexto histórico de atuantes em qualidade, traduz-se em potencial inovador. Os fatos resumidos nesse artigo dão a clara ideia de que deve haver sim, um desejado, interessante e auspicioso grau de alinhamento entre os dois institutos, reforçando, portanto, a hipótese do artigo.

\section{REFERÊNCIAS}

Brasil. Lei no 9.279, de 14 de maio de 1996. Regula Direitos e Obrigações à Propriedade Industrial. Brasília: Diário Oficial da União (DOU). Disponível em: <http://www.planalto.gov.br/
ccivil_03/leis/L9279.htm> Acesso em 30 abr. 2019.

Calzolaio, Aziz Eduardo.; DATHEIN, Ricardo. (2012), Políticas Fiscais de Incentivo à Inovação: Uma Avaliação da Lei do Bem, Porto Alegre, Anais do Encontro de Economia da Região Sul, 15, ANPEC SUL.

Salerno, Mario Sergio. (2012), Sistemas Nacionais de Inovação. Natal, Curso Políticas de Inovação para Gestores Públicos /Cepal-ONU / MCTI.

Cassiolato, José Eduardo.; LASTRES, Maria Lúcia Maciel., (2003), Systems of Innovation and Development, Cheltenham, Elgar.

Chiavenato, Idalberto. (2002), Coaching \& Mentoring: Construção de Talentos - As Novas Ferramentas da Gestão de Pessoas, Rio de Janeiro, Editora Campus, 7a edição.

Cooper, Juett R. (1998), A Multidimensional Approach to the Adoption of Innovation. Bingley, Management Decision, Vol. 38, No. 8, Emerald Insight.

Ishikawa, Kaoru. (1993), Controle de Qualidade Total à Maneira Japonesa, Rio de Janeiro, Editora Campus, 2a Edição.

Maximiano, Antonio César Amaru. (2002), Teoria Geral da Administração - Da Revolução Urbana à Revolução Digital, Vol. 3, São Paulo, Editora Atlas.

Han, S. Bruce; CHEN, Shaw K. e EBRAHIMPOUR, Maling. (2007), The Impact of ISO 9000 on TQM and Business Performance, Oakdale, The Journal of Business and Economic Studies, Vol. 13, No. 2.

Prajogo, Daniel; Sohal, Amrik Singh. (2003), The Relationship between TQM Practices, Quality Performance, and Innovation Performance, Bingley, International Journal of Quality \& Reliability Management, Vol. 20, No. 8.

(2004a). "The Multidimensionality of TQM Practices in Determining Quality and Innovation Performance - An Empirical Examination". Amsterdam, Technovation, Vol. 24, No. 6.

(2004b). Transitioning from Total Quality Management to Total Innovation Management: Australian Case, Bingley, International Journal of Quality \& Reliability Management, Vol. 21, No. 8.

Santos, Jorge Marques dos. (2013), Qualidade e Inovação, Uma Relação Biunívoca. Porto, Instituto Português da Qualidade - IPQ, Associação de Antigos Orfeonistas da Universidade do Porto - AAOUP.

Westphal, James D.; GULATI, Ranjay \& SHORTELL, Stephen M. (1997), Customization or Conformity? Na institutional and Network Perspective on the Content and Consequences of TQM Adoption, Newcastle upon Tyne, Administrative Science Quarterly, Vol. 42, No. 2, Jun.

Yamin, Sharid; MAVONDO, Felix.; GUNASEKARAN, Angappa \& SARROS, James C. (1997). A Study of Competitive Strate- 
gy, Organizational Innovation and Organization Performance among Australian Manufacturing Companies, Amsterdam, International Journal of Production Economics, Vol. 52.

ANPEI. (2015), 8 das 10 Empresas mais Inovadoras do País são Associadas à Anpei, São Paulo, Associação Nacional de Pesquisa e Desenvolvimento das Empresas Inovadoras - ANPEI, disponível em <http://anpei.org.br/destaques/8-das-10-empresas-mais-inovadoras-pais-sao-associadas-anpei/> Acesso em: 15 mar. 2019.

Matias-pereira, José \& Kruglianskas, Isak. (2005), Gestão de Inovação: A Lei de Inovação Tecnológica como Ferramenta de Apoio às Políticas Industrial e Tecnológica do Brasil, São Paulo, RAE-eletrônica, Vol. 4 (Julio-Diciembre). Disponível em: <http://www.redalyc.org/articulo. oa?id=205114650003> Acesso em: 01 fev. 2019.

Oliveira, Marcus Antonio de. (2015), A ISO 90012015 e a Inovação. São Paulo, SGQ Consultoria, disponível em: <https:// www.iso9001.com.br/iso-9001-2015-inovacao/> Acesso em: 29 jan. 2019.

Salerno, Mario Sergio. (2016), O Novo Marco Legal de Ciência, Tecnologia e Inovação. Brasília, Serviço Brasileiro de Apoio às Micro e Pequenas Empresas - SEBRAE, disponível em:<http:// www.sebrae.com.br/sites/PortalSebrae/artigos/o-novo-marco-legal-de-ciencia-tecnologia-e-inovacao,8603f03e7f484610 VgnVCM1000004c00210aRCRD> Acesso em: 30 abr. 2019
Saraiva, Pedro M. e D’Orey, João. (1999), Inovação e Qualidade, Porto, Princípia, Sociedade Português da Inovação, disponível em: <http://www.spi.pt/documents/books/inovint/ iq/conteudo_integral/acesso_conteudo_integral/acc_int_sel. htm>. Acesso em: 09 jan. 2019.

SEBRAE. (2004), Cartilha Gestão da Inovação - Mobilização Empresarial pela Inovação, Brasília, Serviço Brasileiro de Apoio às Micros e Pequenas Empresas - SEBRAE, disponível em:<https://bucket-gw-cni-static-cmssi.s3.amazonaws.com/ media/filer_public/9d/16/9d16abac-a115-4758-b4dc-9a3e3 d21a8d0/20121126110821586027u.pdf>. Acesso em: 01 fev. 2019.

Zairi, Mohamed; Letza, Stephen \& Oakland, J. S. (1994), Does TQM Impact on Bottom-Line Results? Bingley, TQM Magazine, Vol. 6, No. 1, disponível em: https://www.strategyand. pwc.com/br/inovacao-brasil\#Ranking Acesso em: 15 mar. 2019.

Fonseca, Carmen Lúcia Couto. (2004), Gestão da Qualidade x Gestão do Conhecimento: Um Estudo na CHESF. Dissertação de Mestrado, Recife, Programa de Mestrado Profissionalizante em Gestão Pública para o Desenvolvimento do Nordeste MPANE, Universidade Federal do Pernambuco - UFPE.

Lima, Wander Demonel de. (2011), Gestão da Cadeia de Valor da Inovação em Empresas Low-Tech. (Tese de Doutorado em Engenharia da Produção). São Paulo: Escola Politécnica da Universidade de São Paulo, Departamento de Engenharia de Produção.

Recebido: 09 jan. 2020

Aprovado: 09 mar. 2021

DOI: 10.20985/1980-5160.2021.v16n1.1604

Como citar: Jamal, C.M.C., Anversa, M.V.A., Chacon, P.A.S. (2020). A conexão do Sistema de Gestão da Qualidade Total (SGQ) com a Gestão da Inovação (GI). Revista S\&G 16, 1, 3-10. https://revistasg.emnuvens.com.br/sg/article/ view/1604 